\title{
New Ther1-derived SINE Squam3 in scaled reptiles
}

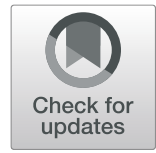

\author{
Nikita S. Vassetzky ${ }^{1,2^{*}}$ D, Sergei A. Kosushkin ${ }^{2}$, Vitaly I. Korchagin ${ }^{1}$ and Alexey P. Ryskov ${ }^{1}$
}

\begin{abstract}
Background: SINEs comprise a significant part of animal genomes and are used to study the evolution of diverse taxa. Despite significant advances in SINE studies in vertebrates and higher eukaryotes in general, their own evolution is poorly understood.

Results: We have discovered and described in detail a new Squam3 SINE specific for scaled reptiles (Squamata). The subfamilies of this SINE demonstrate different distribution in the genomes of squamates, which together with the data on similar SINEs in the tuatara allowed us to propose a scenario of their evolution in the context of reptilian evolution.

Conclusions: Ancestral SINEs preserved in small numbers in most genomes can give rise to taxa-specific SINE families. Analysis of this aspect of SINEs can shed light on the history and mechanisms of SINE variation in reptilian genomes.
\end{abstract}

Keywords: SINEs, Retrotransposons, Squamata, Reptilia, Evolution

\section{Background}

Genomes are invaded by various repetitive elements, the most abundant of which (at least in higher eukaryotes) are Long and Short INterspersed Elements (LINEs and SINEs, respectively). The amplification cycle of these retrotransposons includes the transcription of their genomic copies, reverse transcription and integration into the genome. LINEs rely on the transcription by the cellular RNA polymerase II, while reverse transcription and integration are fulfilled by their own enzymes. SINEs do not encode any enzymes and employ the cell machinery for their transcription by RNA polymerase III (pol III) and the machinery of their partner LINE for their reverse transcription and integration into chromosomes. Accordingly, SINEs have pol III promoters for transcription and

\footnotetext{
* Correspondence: nvas@eimb.ru

${ }^{1}$ Institute of Gene Biology, Russian Academy of Sciences, Moscow 119334, Russia

2Engelhardt Institute of Molecular Biology, Russian Academy of Sciences, Moscow 119991, Russia
}

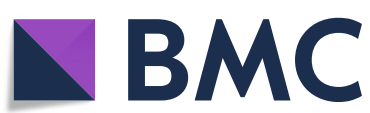

(C) The Author(s). 2021 Open Access This article is licensed under a Creative Commons Attribution 4.0 International License, which permits use, sharing, adaptation, distribution and reproduction in any medium or format, as long as you give appropriate credit to the original author(s) and the source, provide a link to the Creative Commons licence, and indicate if changes were made. The images or other third party material in this article are included in the article's Creative Commons licence, unless indicated otherwise in a credit line to the material. If material is not included in the article's Creative Commons licence and your intended use is not permitted by statutory regulation or exceeds the permitted use, you will need to obtain permission directly from the copyright holder. To view a copy of this licence, visit http://creativecommons.org/licenses/by/4.0/ The Creative Commons Public Domain Dedication waiver (http://creativecommons.org/publicdomain/zero/1.0/) applies to the data made available in this article, unless otherwise stated in a credit line to the data.
LINE for reverse transcription/integration.

A typical SINE consists of the head derived from one of the cellular RNA species (tRNA, 7SL RNA, or 5S RNA); the body, the terminal part of which is recognized by the partner reverse transcriptase (RT); and the tail, a stretch of simple repeats. There are variations; certain SINEs have no body or their body contains sequences of unknown origin and function (some of them called central domains) that are shared between otherwise unrelated SINE families, etc. [1].

LINEs are found in the genomes of all higher eukaryotes. Clearly, SINEs cannot exist without LINEs but not vice versa; there are rare genomes that have LINEs but lack SINEs (e.g., Saccharomyces or Drosophila). During evolution, LINE (sub)families can become inactive and their partner SINEs also cease to amplify. If another LINE family becomes active in a particular genome, replacement of the sequence recognized by its RT can reanimate a SINE [2]. Usually, a genome harbors one or several SINE families; some of them can be inactive and 
were amplified in the ancestors. The analysis of SINE variation in different taxa allows us to use them as reliable phylogenetic markers [3, 4].

The main lineages of the reptile-bird clade are scaled reptiles (Squamata), tuatara (Rhynchocephalia), turtles (Testudines), crocodiles (Crocodilia), and birds (Aves). Squamata, the largest order of reptiles, include the following major lineages: Serpentes (snakes), Iguania (including iguanids, agamids, chameleons), Anguimorpha, Scincomorpha, Lacertoidea, Gekkota, and Amphisbaenia. Phylogenetic relations among squamate reptiles are highly controversial due to the conflicting signals provided by molecular, morphological, and paleontological data. Together with tuatara, the only extant representative species of Rhynchocephalia, they form monophyletic superorder Lepidosauria, which is the sister group to Archelosauria, the clade that contains archosaurs (crocodiles and birds) and turtles [5].

The first reptile SINE was found in 1990 in the Chinese pond turtle [6]; currently, we know approximately ten SINE families in reptiles [1] with a different taxonomic distribution, e.g., Cry is limited to turtles and degraded copies of AmnSINE, which was active in the ancestor of amniotes [7], can be found far beyond reptiles. Another example is Ther1 initially described as a mammalian SINE (MIR) but renamed later [8, 9]. Several known Ther1/MIR subfamilies (MIRb, MIRc, and MIR_Testu) have minor differences from Ther1 except the Alligator mississippiensis's MIR1_ AMi with an extended deletion. Moreover, active Ther1/ MIR SINEs were found in non-avian reptiles, so ample and diverse derived SINEs could be expected in their genomes [10]. This is further corroborated by active diversification of reptilian L2 [11].

Despite active sequencing of genomes of various species of lizards and snakes, no detailed comparative genomic studies of a SINE family in different taxa at the order level are available. We discovered a new SINE named Squam3 in the genomes of Darevskia and Anolis lizards. Further analysis demonstrated their distribution throughout squamates; a similar SINE was found in the tuatara [12] but not in other reptiles or birds. However, Squam3 remained unnoticed in almost 40 genomes of squamates. Here, we analyzed the structure, distribution, and evolution of Squam3 and its relatives.

\section{Results}

\section{Squam3 identification}

The consensus sequence of Darevskia Squam3 was used to search the genomes of scaled reptiles. It was found in all sequenced genomes (as well as in a variety of GenBank sequences of squamate species whose genomes have not been sequenced; Table S1). No Squam3 was found beyond Squamata (see below). The analysis of their consensus sequences has revealed three major subfamilies that we called Squam3A, Squam3B, and Squam3C.

\section{Squam3 structure}

Squam3 is a typical SINE [13] composed of the tRNAderived head, the body with a central domain and the 3 '-terminus matching that of the partner LINE, and the tail, a stretch of several simple repeats. The consensus sequences range from 218 to $239 \mathrm{nt}$ (without tail). There is no clear preference for a particular tRNA species (which is not uncommon among SINEs).

The body is similar to a fragment of the CORE central domain; the pronounced similarity spans over $28 \mathrm{nt}$ (double-overlined in Fig. 1). There is also a similarity with the very 3 '-terminus of LINEs of the L2 clade identified in Darevskia valentini (data not shown) and a less pronounced similarity with L2 LINEs of Anolis carolinensis (L2-26_ACar and L2-24_ACar in Repbase).

The tail of Squam3 is largely composed of (TAAA) $n$ or $(\mathrm{CTT})_{\mathrm{n}}$; however, certain species have $(\mathrm{GTT})_{\mathrm{n}},(\mathrm{ATT})_{\mathrm{n}}$, or poly(A) (Table 1). Squam3 has a very low rate of target site duplications. This is unusual but not exceptional among SINEs and can point to an alternative cleavage pattern in different DNA strands by the partner LINE endonuclease [13].

\section{Squam3 subfamilies}

Genomic copies of SINEs are subject to random mutations; accordingly, single-nucleotide mutations can be used to identify subfamilies only for highly conserved SINEs. We use extended insertions/deletions to distinguish between the three major Squam3 subfamilies designated as Squam3A, Squam3B, and Squam3C (Fig. 1). Squam3B has a characteristic 11-nt insertion (marked in pink in Fig. 1), and Squam3C has a characteristic 7-nt insertion (marked in blue in Fig. 1). There are also minor differences between the Squam3 subfamilies. In addition, there are sub-subfamilies; one of these (Squam3B3) has become a major variant in the two Gekkonidae species.

Further analysis of Squam3-related sequences in the tuatara genome has revealed a similar SINE (tuaMIRa) with a 32-nt insertion (marked in amaranth in Fig. 1). This insertion restores the CORE central domain and makes the element similar to Ther1 (MIR). It should be noted that this deletion in Squam3 and tuaMIRc relative to Ther1 is distinct from the deletion in MIR1_AMi (Fig. S2A). TuaMIR SINEs also have an 8-13-nt deletion in the LINE-derived region (marked in violet in Fig. 1). Moreover, another element (tuaMIRb) with a similar insertion lacks the $\sim 40$-nt region between the CORE and the LINE-derived region conserved in other Squam3- 


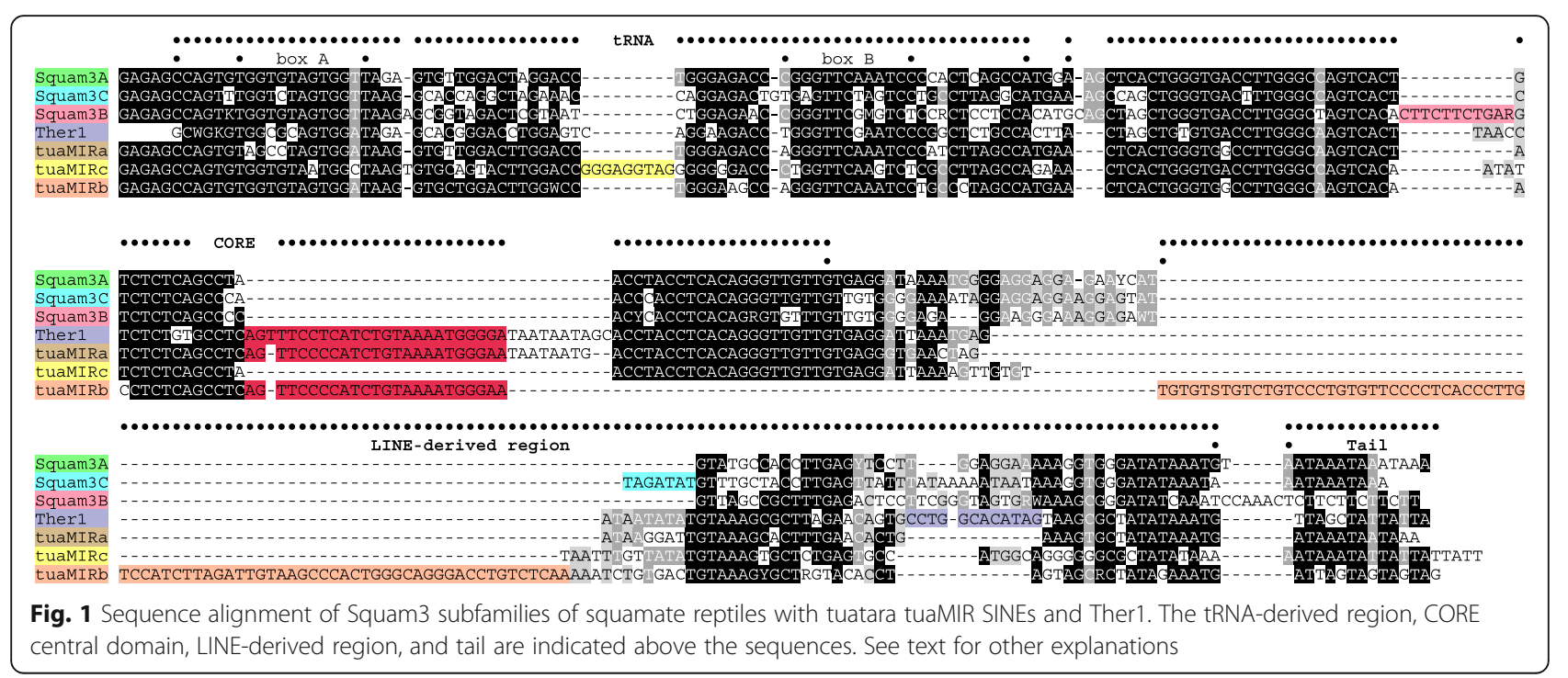

and Ther1-related SINEs but has a much longer L2 LINE-derived region due to the 77-nt insertion (marked in mango in Fig. 1). The sequences of these tuatara SINE families were recently reported [12] but only the relation to MIR (former name of Ther1) and the mean divergence of all Ther1-related sequences were mentioned.

Apart from that, Squam3 subfamilies differ by the tail, which is largely (TAAA) $)_{n}$ in Squam3A/C or $(\text { CTT })_{n}$ in Squam3B. The mean sequence similarity also differs between subfamilies, it peaks in Squam3B (up to 94\%) but is lower in Squam3C ( 63\%) and Squam3A (54-63\%). Figure 2 visualizes the diversity of Squam 3 in the genomes of lizards, snakes, and tuatara. Squam $3 \mathrm{C}$ in most snake species demonstrates little variation between species; this contrasts with the diversity within Squam3A and Squam3B subfamilies. The tuatara SINEs clearly constitute a cluster separate from Ther1.

The number of Squam3 full-length copies varied over a wide range: from $\sim 500$ in Anolis carolinensis to $\sim 260$, 000 in Gekko japonicas ( 0.005 and $2.55 \%$ of the genomes by length, respectively) (Fig. 3). The mean similarity of Squam3 subfamilies in most species is $60-65 \%$ with the notable exceptions of Squam3B ( 90\%) and Squam3A in Iguania (53\%).

\section{Distribution of Squam3 in reptile genomes}

We next searched for the consensus sequences of Squam3 subfamilies in genomes of squamates and neighboring taxa. Overall, the genomes of 38 squamates, tuatara, turtle (Trachemys scripta elegans), crocodile (Crocodylus porosus), and bird (Gallus gallus) were analyzed. Squam3 was found in all squamates but neither in other reptiles nor in birds (Table 1). Similar SINE families were found in the tuatara (Sphenodon punctatus). When this work was in progress, Gemmel et al. [12] reported these SINEs, so we use their nomenclature of tuatara SINEs.

The genomes of Gekkota and Lacertoidea (Gekkonidae, Eublepharidae, Lacertidae, and Teiidae families) had both Squam3A and Squam3B subfamilies in similar proportions (although the proportion of Squam3A could be occasionally as low as 12\%). Snakes had the Squam3C subfamily except for the python, which had 43\% Squam3A. The rest of the squamates (Shinisauridae, Anguidae, Varanidae, Agamidae, and Dactyloidae families) had the Squam3A subfamily alone (Table 1). The analysis of individual NCBI sequences of squamate species not listed in Table 1 largely confirms this pattern except that a few highly divergent Squam3A sequences were found in three more snake families (Elapidae, Lamprophiidae, and Viperidae) (Table S1). We specifically searched for Squam3A in one of the advanced snakes (Vipera berus), and found $\sim 330$ copies.

The tuatara (Sphenodontidae) has a set of tuaMIR families related to Squam3 and Ther1. Thus, we specifically searched for these sequences in the genomes of Squamata. No tuaMIRb or tuaMIRc were found, while minor tuaMIRa quantities exist in all squamate genomes analyzed ranging from a single full-length copy to $\sim 500$ (in Shinisaurus crocodilurus) (Table S2). All snakes have a single tuaMIRa copy in the same genomic locus (as judged by very similar flanking regions).

\section{Squam3 and other similar CORE SINEs}

We compared Squam3 with tuaMIR and other COREcontaining SINEs of vertebrates. While the 5 '-sequences of all COREs are similar, the characteristic deletion (marked in amaranth in Fig. 1) distinguishes all Squam3 and tuaMIRc from other SINEs (Fig. S2C). 


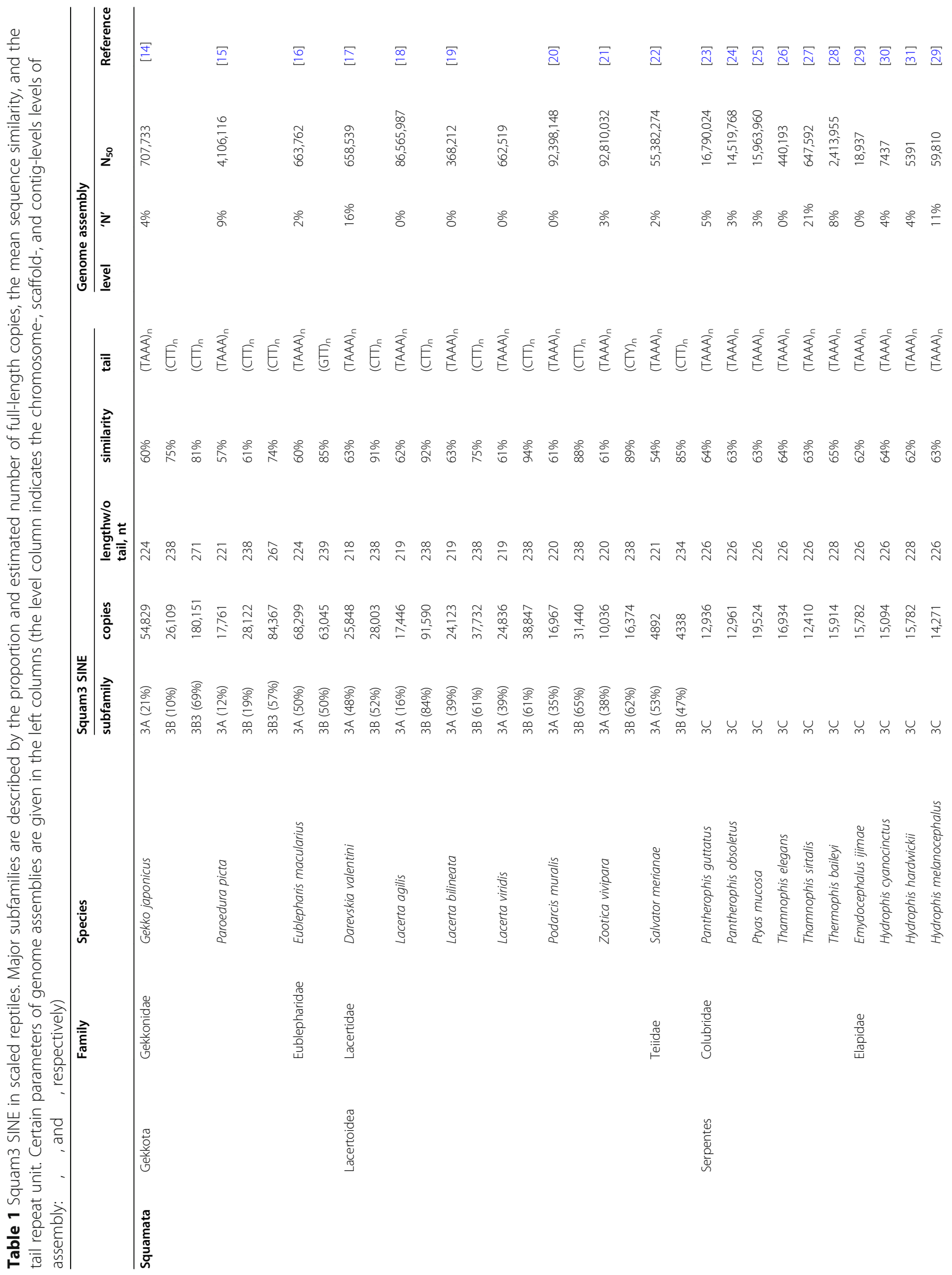




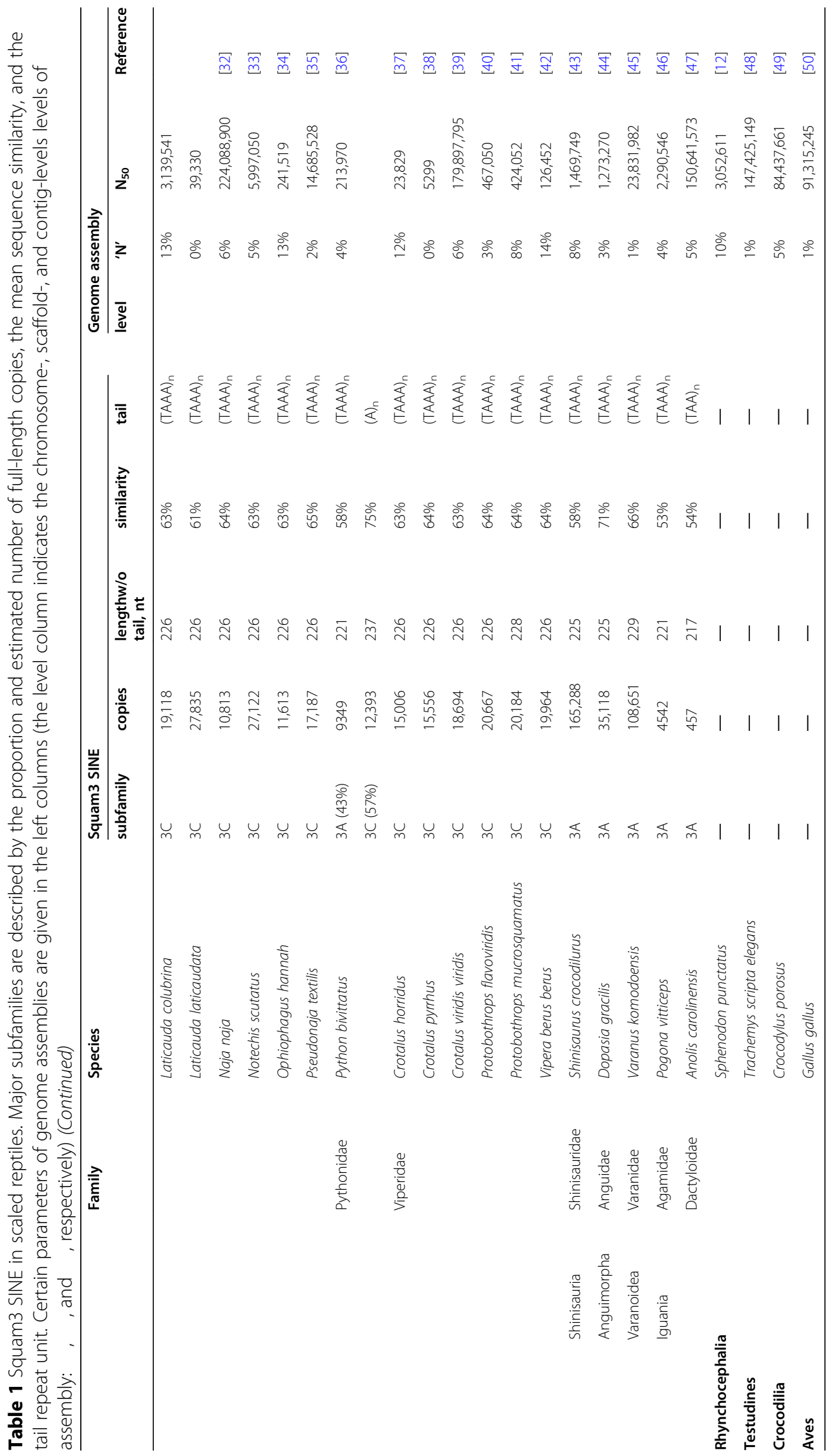




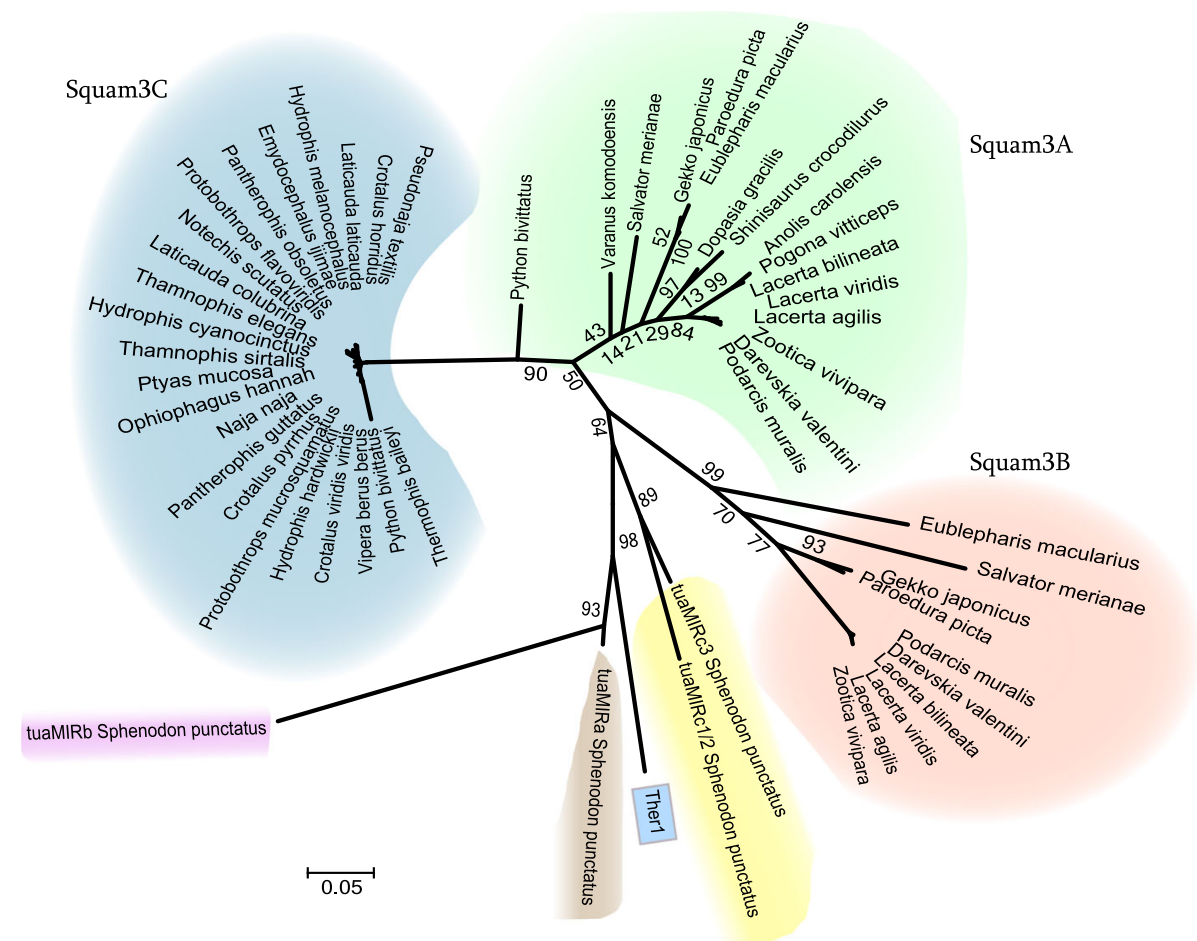

Fig. 2 Unrooted NJ tree of consensus sequences of Squam3 and tuaMIR SINES

\section{Discussion}

One of the most intriguing aspects of SINEs is how they emerged and evolved. This study gives us a unique opportunity to trace this for a single SINE family in a very wide range of taxa. The Squam3 SINE was found in scaled reptiles (Squamata) but not in the tuatara (Rhynchocephalia) and further lineages including crocodiles, birds, and turtles. We found three major subfamilies distinguished by relatively long insertions/deletions (Squam3A, Squam3B, and Squam3C). They also differ by the number of copies and the mean sequence similarity, which points to the age of a SINE subfamily (to be precise, to the time of its amplification) since SINE genomic copies are not subject to selective pressure and gradually accumulate mutations with time.

\section{Evolution of Squam3}

Overall, presumably there was a small pool (a few hundred?) of not very active Squam3A in the genomes of ancestral Squamata. In some lineages (Shinisauridae and Varanidae), Squam3A amplified quite actively without significant sequence modifications (to reach $\sim 165,000$ copies in Shinisaurus crocodilurus; the number of Squam3 copies was higher only in the Gekko japonicus with a $\sim$ twice larger genome). Squam3A amplification was also active in Anguidae ( 35,000 copies in Dopasia gracilis) but it started relatively recently considering the high mean similarity (71\%) of the SINE sequences in this legless lizard. On the contrary, Squam3A gradually declined in Agamidae ( 4500 copies and 53\% mean similarity in Pogona vitticeps). Finally, Squam3A ceased to propagate (and evolve) in Dactyloidae $(<500$ copies in Anolis carolinensis).

While other Squam3 subfamilies emerged in squamate lineages, Squam3A continued to amplify in Gekkota and Lacertoidea (from $\sim 5000$ to $\sim 65,000$ copies) but not in snakes (except primitive ones, $\sim 9000$ in Python bivittatus). We could find only 300 copies in Vipera berus; individual copies were also found in non-genomic sequences of four other snake families (Table S2).

After Squam3A declined in the Gekkota and Lacertoidea, their genomes gave rise to the Squam3B subfamily. It is arguably the youngest Squam3 subfamily. Amazingly, the mean similarity of Squam3B is very high in $\mathrm{La}$ certa agilis (92\%) and L. viridis (94\%) but as low as $75 \%$ in $L$. bilineata. This indicates that Squam3B is likely active in $L$. viridis and $L$. agilis but not in $L$. bilineata representing the same genus. In Gekkonidae, the more prolific Squam3B3 sub-subfamily emerged $(\sim 180,000$ copies in Gekko japonicus, which is the highest number of all Squam3 subfamilies). For some reason, the activity of both Squam3A and Squam3B was low in Teiidae (Salvator merianae) but still, Squam3B amplified later than Squam3A.

The Squam3C subfamily is limited to snakes; moreover, it is the only major subfamily in most snakes. 


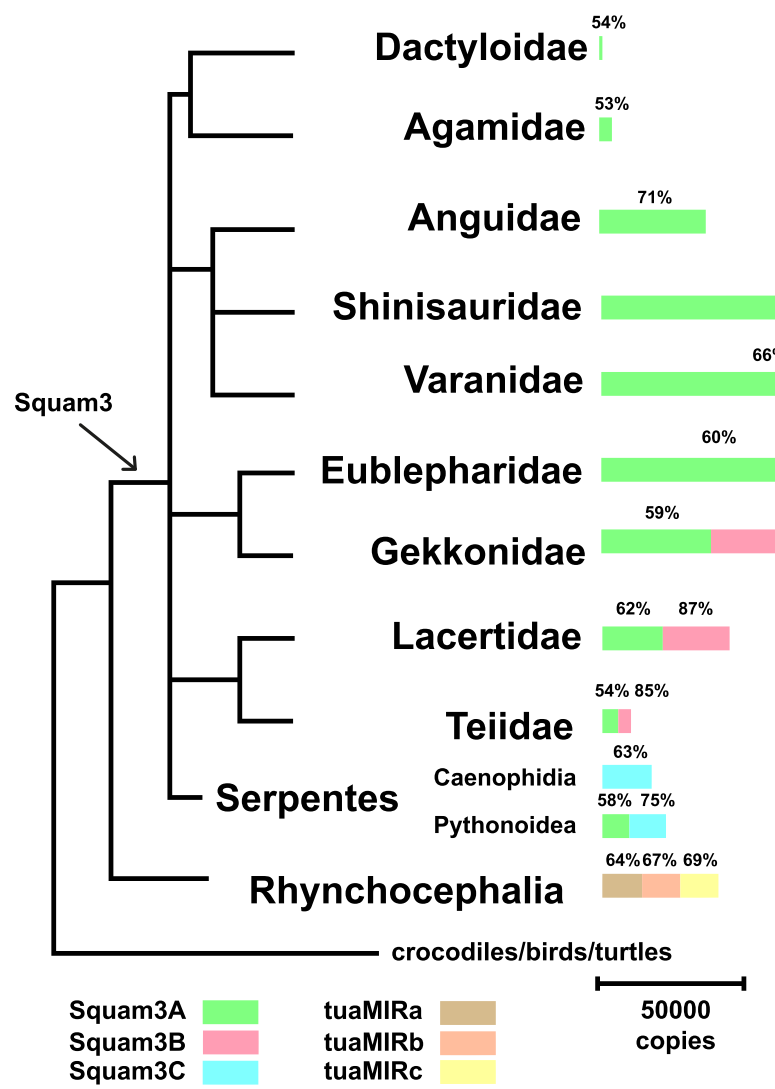

Fig. 3 Schematic distribution of Squam3 SINEs in Squamata lineages studied. Colored band lengths are proportional to their copy numbers in genomes and the numbers above indicate the mean similarity of individual copies. If more than one species was available, the mean values are given

Squam3A quantities were probably present in all squamates but did not propagate in most snakes. Instead, the Squam3C in advanced snakes (Caenophidia) became active slightly later or in the same period of time (the mean Squam3C similarity is $61-65 \%$ vs. $51-71 \%$ in Squam3A). This pattern is not true for Python bivittatus representing more primitive snakes, where the amplification of Squam3A was followed by that of Squam3C (with the mean similarities of 58 and $75 \%$, respectively).

\section{Origin of Squam3}

We were very excited to find what is called the "missing link" of Sqaum3 evolution in the tuatara. The genome of Sphenodon punctatus has three SINE families that are similar to Squam3 in the leftmost 120 nt except the 32nt deletion in Squam3 relative to two of them (tuaMIRa and tuaMIRb). Thus, a large CORE fragment was deleted in two tuaMIR SINEs. Another tuatara SINE (tuaMIRc) has this deletion and is similar to Squam3 within this region (but differs in the head and LINE-derived regions). It is plausible that the ancestor of Ther1 that was active in the common ancestor of mammals, reptiles, birds, and even coelacanth $[9,51]$ acquired the 32-nt deletion within the CORE domain in the Lepidosauria ancestor and the same region is present in related SINEs (Figs. S2B and $\mathrm{S} 2 \mathrm{C})$. This precursor SINE gave rise to tuaMIRc in the tuatara and Squam3 in Squamata.

\section{Conclusions}

We discovered a new SINE Squam3 found in all (38 to the time of analysis) sequenced genomes of scaled reptiles (Squamata). Despite the ever-increasing amount of genomic data for lizards and snakes, this quite prolific SINE was not reported previously. The evolutionary dynamics of SINE families and subfamilies is obscure and linked to the divergence of the genomes. This study is a step forward in understanding how SINEs emerge and decline. We identified and described Squam3 subfamilies and directly compared their structural traits and copy number across a variety of major squamate taxa in comparison with related tuatara SINE families. This study gives an insight into how SINE families emerge and evolve.

\section{Methods}

Most genomic data were downloaded from NCBI Genomes (https://www.ncbi.nlm.nih.gov/genome) except 
Anolis carolinensis, Podarcis muralis (Ensembl, https:// www.ensembl.org), Dopasia gracilis, Shinisaurus crocodilurus (diArk, https://www.diark.org/diark), and Darevskia valentini [17]. We used the genomic sequences of Lacerta agilis and Thamnophis elegans with permission from the Vertebrate Genomes Project. Individual sequences of squamate species not listed in Table 1 were also extracted from NCBI (https://www.ncbi.nlm.nih. gov/taxonomy/advanced). If no data on the genome size was available in publications or the Animal Genome Size Database [52], it was calculated as the mean of most close species.

We used custom Perl scripts based on the SmithWaterman search to find genomic copies of SINEs with at least $65 \%$ identity and $90 \%$ length overlap with the consensus. After all Squam3 families were identified, the genome bank was successively depleted using their consensus sequences and all hits were combined for further analysis.

Multiple sequence alignments were generated using MAFFT [53] and edited by GeneDoc [54]. Subfamilies were identified manually and analyzed in a larger sample if necessary. We considered only ample subfamilies $(\geq 1 \%$ of the total number of full-length copies). A search for tuaMIR SINEs in reptile/bird genomes was carried out by initial identification of all copies with at least $65 \%$ similarity to the consensus sequences followed by manual subsampling and realigning of candidate copies possibly containing specific mutations separating them from tuaMIRa sequences. The mean similarity was determined for 100 randomly selected sequences (or all available if less) using the alistat program (Eddy S., Cambridge, [55]). A neighbor-joining tree was constructed using MEGA software with 1000 bootstrap replications and the "partial deletion" option.

\section{Supplementary Information}

The online version contains supplementary material available at https://doi. org/10.1186/s13100-021-00238-y.

\footnotetext{
Additional file 1: Fig. S1. Alignment of species-specific Squam3 sequences. Green, Squam3A; red, Squam3B; blue - Suam3C. Species designations are: Squam3EmA, Eublepharis macularius; Squam3GjA, Gekko japonicus; Squam3PpA, Paroedura picta; Squam3Vk, Varanus komodoensis; Squam3Ch, Crotalus horridus; Squam3Pt, Pseudonaja textilis; Squam3Cp, Crotalus pyrrhus; Squam3Pg, Pantherophis guttatus; Squam3Nn, Naja naja; Squam3Oh, Ophiophagus hannah; Squam3Pmc, Protobothrops mucrosquamatus; Squam3Ts, Thamnophis sirtalis; Squam3Hc, Hydrophis cyanocinctus; Squam3Te, Thamnophis elegans; Squam3Pf, Protobothrops flavoviridis; Squam3Po, Pantherophis obsoletus; Squam3Cv, Crotalus viridis; Squam3Hh, Hydrophis hardwickii; Squam3Tb, Thermophis baileyi; Squam3Vb, Vipera berus; Squam3Ej Emydocephalus ijimae; Squam3Hm, Hydrophis melanocephalus; Squam3LI, Laticauda laticaudata; Squam3Lc, Laticauda colubrina; Squam3Ns, Notechis scutatus; Squam3Pr, Protobothrops mucrosquamatus; Squam3PbC, Python bivittatus; Squam3DvB, Darevskia valentini; Squam3LbB, Lacerta bilineata; Squam3LaB, Lacerta agilis; Squam3LvB, La certa viridis; Squam3PmB, Podarcis muralis; Squam3ZvB, Zootica vivipara; Squam3GjB, Gekko japonicus; Squam3PpB and Squam3PpB3, Paroedura
}

picta; Squam3GjB3, Gekko japonicus; Squam3EmB, Eublepharis macularius; Squam3SmB, Salvator merianae.

Additional file 2: Fig. S2. A. Alignment of Ther1/MIR subfamilies. B. Comparison of full-length consensus sequences of Squam3, tuaMIR and other CORE SINES with tRNA- and L2-derived regions. The corresponding regions are indicated above the sequences. C. CORE domains of CORE SINEs in vertebrates. The characteristic Squam3 deletion is marked in amaranth (as in Fig. 1).

Additional file 3: Fig. S3. Alignment of LINE-derived regions of tuaMIRb and Ther1 and 3'-terminal sequences of several L2 LINEs. The origin and total length is given in parentheses.

Additional file 4: Table S1. Squam3 copies found in individual NCBI sequences of squamate species not listed in Table 1.

Additional file 5: Table S2. Distribution of tuaMIR subfamilies in genomes of animals studied.

Acknowledgments

We thank Dr. Dmitri Kramerov for critical reading of the manuscript.

Authors' contributions

NSV and APR, conceptualization; all, genomic data analysis; NSV and SAK, study design and manuscript preparation; APR and VIK, supervision; APR, project administration and funding acquisition. All authors read and approved the final manuscript.

\section{Funding}

This research was funded by the Russian Science Foundation (RSF) Project No. 19-14-00083.

\section{Availability of data and materials}

The data generated are available in the manuscript supporting files. The banks of Squam3 SINEs, as well as multiple alignments of random sets of SINE sequences, are available for each species on request.

\section{Declarations}

Ethics approval and consent to participate

Not applicable.

\section{Consent for publication}

Not applicable.

\section{Competing interests}

The authors declare that they have no competing interests.

Received: 16 December 2020 Accepted: 25 February 2021

Published online: 22 March 2021

\section{References}

1. Vassetzky NS, Kramerov DA. SINEBase: a database and tool for SINE analysis. Nucleic Acids Res. 2013;41:D83-9 [cited 2014 Jun 4]. Available from: http:// www.pubmedcentral.nih.gov/articlerender.fcgi?artid=3531059\&tool= pmcentrez\&rendertype=abstract.

2. Kramerov DA, Vassetzky NS. Origin and evolution of SINEs in eukaryotic genomes. Heredity (Edinb). 2011;107:487-95 Available from: http://www. ncbi.nlm.nih.gov/entrez/query.fcgi?cmd=Retrieve\&db=PubMed\&dopt=Cita tion\&list uids $=21673742$

3. Shedlock AM, Takahashi K, Okada N. SINEs of speciation: tracking lineages with retroposons. Trends Ecol Evol. 2004;19:545-53 Available from: http:// www.ncbi.nlm.nih.gov/entrez/query.fcgi?cmd=Retrieve\&db=PubMed\&dopt= Citation\&list uids $=16701320$.

4. Suh A, Bachg S, Donnellan S, Joseph L, Brosius J, Kriegs JO, et al. De-novo emergence of SINE retroposons during the early evolution of passerine birds. Mob DNA Mobile DNA. 2017:8:1-8.

5. Crawford NG, Parham JF, Sellas AB, Faircloth BC, Glenn TC, Papenfuss TJ, et al. A phylogenomic analysis of turtles. Mol Phylogenet Evol. 2015;83:250-7 Elsevier Inc. Available from: https://doi.org/10.1016/j.ympev.2014.10.021.

6. Endoh $\mathrm{H}$, Nagahashi S, Okada N. A highly repetitive and transcribable sequence in the tortoise genome is probably a retroposon. Eur J Biochem. 
1990;189:25-31 Available from: http://www.ncbi.nlm.nih.gov/pubmed/169 979.

7. Nishihara H, Smit AF, Okada N. Functional noncoding sequences derived from SINEs in the mammalian genome. Genome Res. 2006;16:864-74 Available from: http://www.ncbi.nlm.nih.gov/entrez/query.fcgi?cmd= Retrieve\&db=PubMed\&dopt=Citation\&list_uids $=16717141$.

8. Smit AF, Riggs AD. MIRs are classic, tRNA-derived SINEs that amplified before the mammalian radiation. Nucleic Acids Res. 1995;23:98-102 Available from: http://www.ncbi.nlm.nih.gov/pubmed/7870595.

9. Gilbert N, Labuda D. Evolutionary inventions and continuity of CORE-SINEs in mammals. J Mol Biol. 2000;298:365-77 Available from: http://www.ncbi. $\mathrm{nlm}$.nih.gov:80/entrez/query.fcgi?cmd=Retrieve\&db=PubMed\&list_uids= 10772856\&dopt=Abstract.

10. Shedlock AM, Botka CW, Zhao S, Shetty J, Zhang T, Liu JS, et al. Phylogenomics of nonavian reptiles and the structure of the ancestral amniote genome. Proc Natl Acad Sci U S A. 2007;104:2767-72.

11. Shedlock AM. Phylogenomic investigation of CR1 LINE diversity in reptiles. Syst Biol. 2006;55:902-11.

12. Gemmell NJ, Rutherford K, Prost S, Tollis M, Winter D, Macey JR, et al. The tuatara genome reveals ancient features of amniote evolution. Nature. 2020; 584:403-9.

13. Kramerov DA, Vassetzky NS. SINEs. Wiley Interdiscip Rev RNA. 2011;2:772-86 [cited 2014 Jun 4]. Available from: http://www.ncbi.nlm.nih.gov/pubmed/21 976282

14. Liu Y, Zhou Q, Wang Y, Luo L, Yang J, Yang L, et al. Gekko japonicus genome reveals evolution of adhesive toe pads and tail regeneration. Nat Commun. 2015;6 Nature Publishing Group. [cited 2020 Nov 29]. Available from: https://pubmed.ncbi.nlm.nih.gov/26598231/.

15. Hara Y, Takeuchi M, Kageyama Y, Tatsumi K, Hibi M, Kiyonari H, et al. Madagascar ground gecko genome analysis characterizes asymmetric fates of duplicated genes. BMC Biol BMC Biology. 2018;16:1-19.

16. Xiong Z, Li F, Li Q, Zhou L, Gamble T, Zheng J, et al. Draft genome of the leopard gecko, Eublepharis macularius. GigaScience. 2016;5 Available from: https://doi.org/10.1186/s13742-016-0151-4

17. Darevskia (ID 327916) - BioProject - NCBI [Internet]. [cited 2020 Dec 9]. Available from: https://www.ncbi.nlm.nih.gov/bioproject/327916

18. GenomeArk - Lacerta agilis [Internet]. [cited 2020 Dec 2]. Available from: https://vgp.github.io/genomeark/Lacerta_agilis/

19. Kolora SRR, Weigert A, Saffari A, Kehr S, Walter Costa MB, Spröer C, et al. Divergent evolution in the genomes of closely related lacertids, Lacerta viridis and L. bilineata, and implications for speciation. Gigascience. 2019;8:22 NLM (Medline). [cited 2020 Nov 29]. Available from: http://orcid.org/00000001-7839-735X.

20. Andrade P, Pinho C, De Lanuza GPI, Afonso S, Brejcha J, Rubin CJ, et al. Regulatory changes in pterin and carotenoid genes underlie balanced color polymorphisms in the wall lizard. Proc Natl Acad Sci U S A. 2019;116:563342 [cited 2020 Dec 2]. National Academy of Sciences. Available from: https://www.pnas.org/content/116/12/5633.

21. Yurchenko AA, Recknagel H, Elmer KR. Chromosome-level assembly of the common lizard (Zootoca vivipara) genome. Genome Biol Evol. 2020;12:1953-60.

22. Roscito JG, Sameith K, Pippel M, Francoijs KJ, Winkler S, Dahl A, et al. The genome of the tegu lizard Salvator merianae: combining Illumina, PacBio, and optical mapping data to generate a highly contiguous assembly. Gigascience Oxford University Press. 2018;7:1-13.

23. Ullate-Agote A, Milinkovitch MC, Tzika AC. The genome sequence of the corn snake (Pantherophis guttatus), a valuable resource for EvoDevo studies in squamates. Int J Dev Biol. 2014;58:881-8.

24. Pantherophis obsoletus (ID 88953) - Genome - NCBI [Internet]. [cited 2020 Dec 2]. Available from: https://www.ncbi.n/m.nih.gov/genome/88953 ?genome_assembly_id=889057

25. Ptyas mucosa (ID 44753) - Genome - NCBI [Internet]. [cited 2020 Dec 2]. Available from: https://www.ncbi.nlm.nih.gov/genome/44753?genome_a ssembly_id $=884075$

26. GenomeArk - Thamnophis elegans [Internet]. [cited 2020 Dec 2]. Available from: https://vgp.github.io/genomeark/Thamnophis_elegans/

27. Thamnophis sirtalis (ID 16688) - Genome - NCBI [Internet]. [cited 2020 Dec 2]. Available from: https://www.ncbi.nlm.nih.gov/genome/16688?genome_a ssembly_id $=245767$

28. Li JT, Gao YD, Xie L, Deng C, Shi P, Guan ML, et al. Comparative genomic investigation of high-elevation adaptation in ectothermic snakes. Proc Natl Acad Sci U S A. 2018;115:8406-11.
29. Kishida T, Go Y, Tatsumoto S, Tatsumi K, Kuraku S, Toda M. Loss of olfaction in sea snakes provides new perspectives on the aquatic adaptation of amniotes. Proc R Soc B Biol Sci. 2019;286.

30. Hydrophis cyanocinctus (ID 75161) - Genome - NCBI [Internet]. [cited 2020 Dec 2]. Available from: https://www.ncbi.nlm.nih.gov/genome/75161 ?genome_assembly_id=437861

31. Hydrophis hardwickii (ID 75162) - Genome - NCBI [Internet]. [cited 2020 Dec 2]. Available from: https://www.ncbi.nlm.nih.gov/genome/75162?genome_a ssembly_id=437862

32. Suryamohan K, Krishnankutty SP, Guillory J, Jevit M, Schröder MS, Wu $\mathrm{M}$, et al. The Indian cobra reference genome and transcriptome enables comprehensive identification of venom toxins. Nat Genet. 2020;52:106-17 Springer US. Available from: https://doi.org/10.1038/ s41588-019-0559-8

33. Notechis scutatus (ID 14408) - Genome - NCBI [Internet]. [cited 2020 Dec 2]. Available from: https://www.ncbi.nlm.nih.gov/genome/14408?genome_a ssembly_id=408294

34. Vonk FJ, Casewell NR, Henkel CV, Heimberg AM, Jansen HJ, McCleary RJR, et al. The king cobra genome reveals dynamic gene evolution and adaptation in the snake venom system. Proc Natl Acad Sci U S A. 2013;110:20651-6.

35. Pseudonaja textilis (ID 72610) - Genome - NCBI [Internet]. [cited 2020 Dec 2]. Available from: https://www.ncbi.nlm.nih.gov/genome/72610?genome_a ssembly_id $=408420$

36. Castoe TA, De Koning APJ, Hall KT, Card DC, Schield DR, Fujita MK, et al. Erratum: The Burmese python genome reveals the molecular basis for extreme adaptation in snakes (Proceedings of the National Academy of Sciences of the United States of America (2013) 110, 51, (20645-20650) DOI: 10.1073/pnas. 1314475110). Proc Natl Acad Sci U S A. 2014;111:3194.

37. Crotalus horridus (ID 16679) - Genome - NCBI [Internet]. [cited 2020 Dec 2]. Available from: https://www.ncbi.nlm.nih.gov/genome/16679?genome_a ssembly_id=274149

38. Gilbert C, Meik JM, Dashevsky D, Card DC, Castoe TA, Schaack S. Endogenous hepadnaviruses, bornaviruses and circoviruses in snakes. Proc $R$ Soc B Biol Sci. 2014;281.

39. Crotalus viridis viridis (ID 71654) - Genome - NCBI [Internet]. [cited 2020 Dec 2]. Available from: https://www.ncbi.nlm.nih.gov/genome/71654?genome_a ssembly_id $=434976$

40. Shibata H, Chijiwa T, Oda-Ueda N, Nakamura H, Yamaguchi K, Hattori S, et al. The habu genome reveals accelerated evolution of venom protein genes. Sci Rep. 2018;8:1-11.

41. Aird SD, Arora J, Barua A, Qiu L, Terada K, Mikheyev AS. Population genomic analysis of a pitviper reveals microevolutionary forces underlying venom chemistry. Genome Biol Evol. 2017;9:2640-9.

42. Vipera berus berus (ID 14467) - Genome - NCBI [Internet]. [cited 2020 Dec 2]. Available from: https://www.ncbi.nlm.nih.gov/genome/14467?genome_a ssembly_id=214193

43. Gao J, Li Q, Wang Z, Zhou Y, Martelli P, Li F, et al. Sequencing, de novo assembling, and annotating the genome of the endangered Chinese crocodile lizard Shinisaurus crocodilurus. Gigascience. 2017;6:1-6.

44. Song B, Cheng S, Sun Y, Zhong X, Jin J, Guan R, et al. A genome draft of the legless anguid lizard, Ophisaurus gracilis. Gigascience. 2015;4:15-7.

45. Lind AL, Lai $Y Y Y$, Mostovoy $Y$, Holloway AK, lannucci A, Mak ACY, et al. Genome of the komodo dragon reveals adaptations in the cardiovascular and chemosensory systems of monitor lizards. Nat Ecol Evol. 2019;3:1241-52 Springer US. Available from: https://doi.org/10.1038/s41559-019-0945-8.

46. Georges A, Li Q, Lian J, O'Meally D, Deakin J, Wang Z, et al. High-coverage sequencing and annotated assembly of the genome of the Australian dragon lizard Pogona vitticeps. GigaScience. 2015;4 Available from: https:// doi.org/10.1186/s13742-015-0085-2.

47. Alföldi J, Di Palma F, Grabherr M, Williams C, Kong L, Mauceli E, et al. The genome of the green anole lizard and a comparative analysis with birds and mammals. Nature. 2011:477:587-91.

48. Brian Simison W, Parham JF, Papenfuss TJ, Lam AW, Henderson JB. An annotated chromosome-level reference genome of the red-eared slider turtle (Trachemys scripta elegans). Genome Biol Evol. 2020;12:456-62.

49. Ghosh A, Johnson MG, Osmanski AB, Louha S, Bayona-Vásquez NJ, Glenn TC, et al. A High-Quality Reference Genome Assembly of the Saltwater Crocodile, Crocodylus porosus, Reveals Patterns of Selection in Crocodylidae. Genome Biol Evol. 2019;12:3635-46 Oxford University Press. [cited 2020 Dec 2]. Available from: https://pubmed.ncbi.nlm.nih. gov/31821505/. 
50. Hillier LW, Miller W, Birney E, Warren W, Hardison RC, Ponting CP, et al. Sequence and comparative analysis of the chicken genome provide unique perspectives on vertebrate evolution. Nature. 2004;432:695-716.

51. Nikaido M, Noguchi H, Nishihara H, Toyoda A, Suzuki Y, Kajitani R, et al. Coelacanth genomes reveal signatures for evolutionary transition from water to land. Genome Res. 2013;23:1740-8.

52. Gregory TR. Animal Genome Size Database. 2020. Available from: http:// www.genomesize.com

53. Yamada KD, Tomii K, Katoh K. Application of the MAFFT sequence alignment program to large data - reexamination of the usefulness of chained guide trees. Bioinformatics. 2016;32:3246-51.

54. Nicholas KB, Nicholas HBJ. GeneDoc: Analysis and Visualization of Genetic Variation 1997. Available from: http://www.nrbsc.org/gfx/genedoc/index. html

55. Eddy S, Cambridge U. SQUID - C function library for sequence analysis; 2005

\section{Publisher's Note}

Springer Nature remains neutral with regard to jurisdictional claims in published maps and institutional affiliations.

Ready to submit your research? Choose BMC and benefit from:

- fast, convenient online submission

- thorough peer review by experienced researchers in your field

- rapid publication on acceptance

- support for research data, including large and complex data types

- gold Open Access which fosters wider collaboration and increased citations

- maximum visibility for your research: over $100 \mathrm{M}$ website views per year

At BMC, research is always in progress.

Learn more biomedcentral.com/submissions 